\title{
EARTHWORK PLANNING AND VISUALISATION OF TIME-LOCATION INFORMATION IN ROAD CONSTRUCTION PROJECTS
}

\author{
R. K. Shah \\ Senior Lecturer, School of the Built Environment, Faculty of Technology and Environment, Liverpool John \\ Moores University, Liverpool, L3 3AF, United Kingdom \\ Email Address: $\underline{\text { r.shah@ljmu.ac.uk }}$
}

\begin{abstract}
Accurate information of locations from visual aspect is vital for efficient resource planning and managing the workspace conflicts in the earthwork operations, which are missing in the existing linear schedules. Hence, the construction managers have to depend on the subjective decisions and intangible imaginingfor resources allocation, workspace conflicts and location-based progress monitoring in the earthwork projects. This has caused uncertainties in planning and scheduling of earthworks, and consequently delays and cost overruns of the projects. To overcome these issues, a framework of computer based prototype model was developed using the theory of location-based planning. This paper focuses on the case study experiments to demonstrate the functions of the model, which includes automatic generation of location-based earthwork schedules and visualisation of cut-fill locations on a weekly basis. The experiment results confirmed the model's capability in identifying precise weekly locations of cut-fill and also visualising the time-space conflicts at the earthwork projects. Hence, the paper concludes that the model is a useful decision supporting tool to improve site productivity and reduce production cost of earthworks in the construction projects like roads and railways.
\end{abstract}

Keywords: Earthworks, cut-fill sections, location-based scheduling information, productivity, visualisation

\section{Introduction}

In comparison with other production industries, the construction industry has distinctive features in terms of one-off projects, site production, and temporary organisation [1]. The planning and scheduling process of a construction project is a challenging task and the decisions taken in this stage have the foremost impact on the successful execution of a project from its early conceptual stage to the project completion and operational stage [2]. Planning and scheduling involve careful allocation of resources, particularly along linear construction projects when and where necessary throughout the construction operations. Failure to decide on the optimum work activities with the required resources from location aspects have an adverse impact on the project cost, time, quality, space conflicts, and safety of site works in the construction projects [3].

Arditiet al. [4] suggested that earthworks projects require a separate planning task for each project due to the distinctive characteristics of earthworks. The effective application of planning and scheduling techniques: such as CPM and PERT are limited because the activities associated with linear construction projects like roads, railways and pipelines are fundamentally different from the general building and housing projects. Most of the activities in road projects are linear activities and needs linear scheduling method. A linear scheduling method has the potential to provide significant enhancement in terms of visual representation from the location aspects, and to progress monitoring because the method allows the project schedulers and construction managers to plan road construction projects visually and determine the controlling activity path and locations [5]. Hence, anew methodology with a computer-based model is introduced in this paper to overcome the above issues. 
This paper presents a computer-based prototype model that generates automatically location-based earthwork schedules, and provides a platform for visualising the scheduling information of earthworks from the location viewpoints, particularly in linear construction projects like road and railways. The research devises a decision-support tool that aids to the construction and planning managers, mainly in resource scheduling and progress monitoring more effectively, and assists them in communicating the scheduling information from the location aspects throughout earthwork operations. In this paper, the location-based scheduling is dubbed as "time-location plan". The remainder of the paper outlines literature review, design a conceptual framework, and details of the prototype model development that includes inputs, processes and outputs. The key outputs of the model are automatic generation of location-based schedules (time-location plan and time-space congestion plan) with optimised quantities of earthworks, particularly in the linear construction projects. Finally, case study experiments from a road construction project were used to demonstrate the purposes of the model.

\section{Literature review}

Generally, at the early stages of construction project, earthworks take place and they have unique characteristics, particularly in linear construction projects like roads, railways and pipelines. They constitute a major component in construction and absorb high costs, and there is a need to deal with haul distances for balancing cutting and filling quantities of earthworks in a cost effective approach [6]. For example, a study of 145 road projects found that earthworks constituent was represented around $19.58 \%$ of the monetary value of the project [7]. The earthworks activities also have direct effects in the sequencing of the rest of road activities since earthwork contributes higher percentage in a project monitoring value. Hence, decisions taken during the planning stage of the earthwork operations have high impact on the overall performance of the project [3].

Mattila and Abraham [8] stated that the subjective division of the repetitive activities from location to location, the inability to schedule the continuity of resources and display the activity rates of progress, and failure to provide any information of the performed works on a project are the key limitations of the Critical Path Method (CPM). Mawdesleyet al.[3] pointed out that CPM networks are more suitable for large complex projects, however, line of balance and linear scheduling methods are more practical for the repetitive and linear construction projects. A linear schedule is used to reduce the interruption of continuous or repetitive activities, to maintain resource continuity, and to determine locations of the activities on any given day from the schedule.

Arditiet al.[9] (2001) suggested that the line of balance technique is an example of linear scheduling method, which is based on the hypothesis that the productivity for an activity is uniform or linear. In other words, the productivity (production rate) of an activity is linear when time is plotted on the vertical axis, and location of an activity on the horizontal axis (or vice versa). The production rate of an activity is the slope of the production line, and is expressed in terms of units/linear meter per time. Scheduling methods such as line of balance, repetitive scheduling method, time-location matrix model, time-space scheduling method, linear scheduling methods, time-distance diagram and linearbalance diagram are known as 'location-based scheduling'. These methods are based on the theory of location-based planning in the management of construction projects [10,11]. This method is important because it provides vital information of working locations throughout the earthwork operations, with the aim of reducing the dependency on the subjective decisions. The correct working locations and timing assist construction managers and planners in resource planning, mobilisation of heavy equipment at require locations and controlling site progress more effectively from location aspects. The linear scheduling methods, however, do not provide exact information of working locations and time throughout the earthwork construction. 
Kenley and Seppanen [10]pointed out that there are mainly two types of scheduling methodologies: an activity-based and a location-based methodology. The location-based methodology is also subdivided into two types: unit-production and location-production scheduling. It is known as an alternative methodology of location-based scheduling, which is based on tracking the continuity of crews working on production tasks. On other hand, DynaRoad [12] developed commercial software for a construction schedule and controlling the earthwork activities in linear projects. This provides the location-based scheduling information for a whole section but lacks to provide weekly information of locations. TILOS, which is time-location planning software for managing linear construction projects, assist invisualisingthe repetitive tasks from location aspects. It also provides the flow of scheduling data in terms of time and location on a construction plan [13]. However, existing timedistance charts, produced by DynaRoad and TILOS do not provide weekly information of locations.

This is imperative for effective planning of resources and reducing the space conflicts at construction sites. Consequently, construction mangers depend on the subjective decision for earthwork scheduling due to the limited information of the working locations. Taking into account previous studies, it is concluded that location-based scheduling, which is based on the theory of location-based methodology, is an effective way of representing the planning and scheduling information of earthwork activities in road projects. From the reviewed literature, it was established that the existing time-distance chart is incapable of providing scheduling information of locations. Therefore, this research examined a new methodology for the automatic generation of location-based scheduling that is capable of providing the weekly or daily location information of earthworks. The next section discusses a framework of a computer-based prototype.

\section{Framework of a prototype}

A general specification of the framework of prototype of earthwork scheduling and visualisation is designed as shown in Fig 1, taking into account of the findings from the literature and industry review [14]. The framework is a state-of-the-art, which is designed by integrating the road design data, sectional quantities, productivity rates and unit cost of cut/fill quantities, and an arithmetic algorithm. This helps to generate location-based schedules of earth work automatically and visualise the weekly scheduling information from the location aspects. The developed prototype has the capability of generating terrain modelling, cut/fill optimisation, weekly progress profiles, and time-space congestion plans, cost profiles and cost S-curves of earthworks in the linear construction projects. 


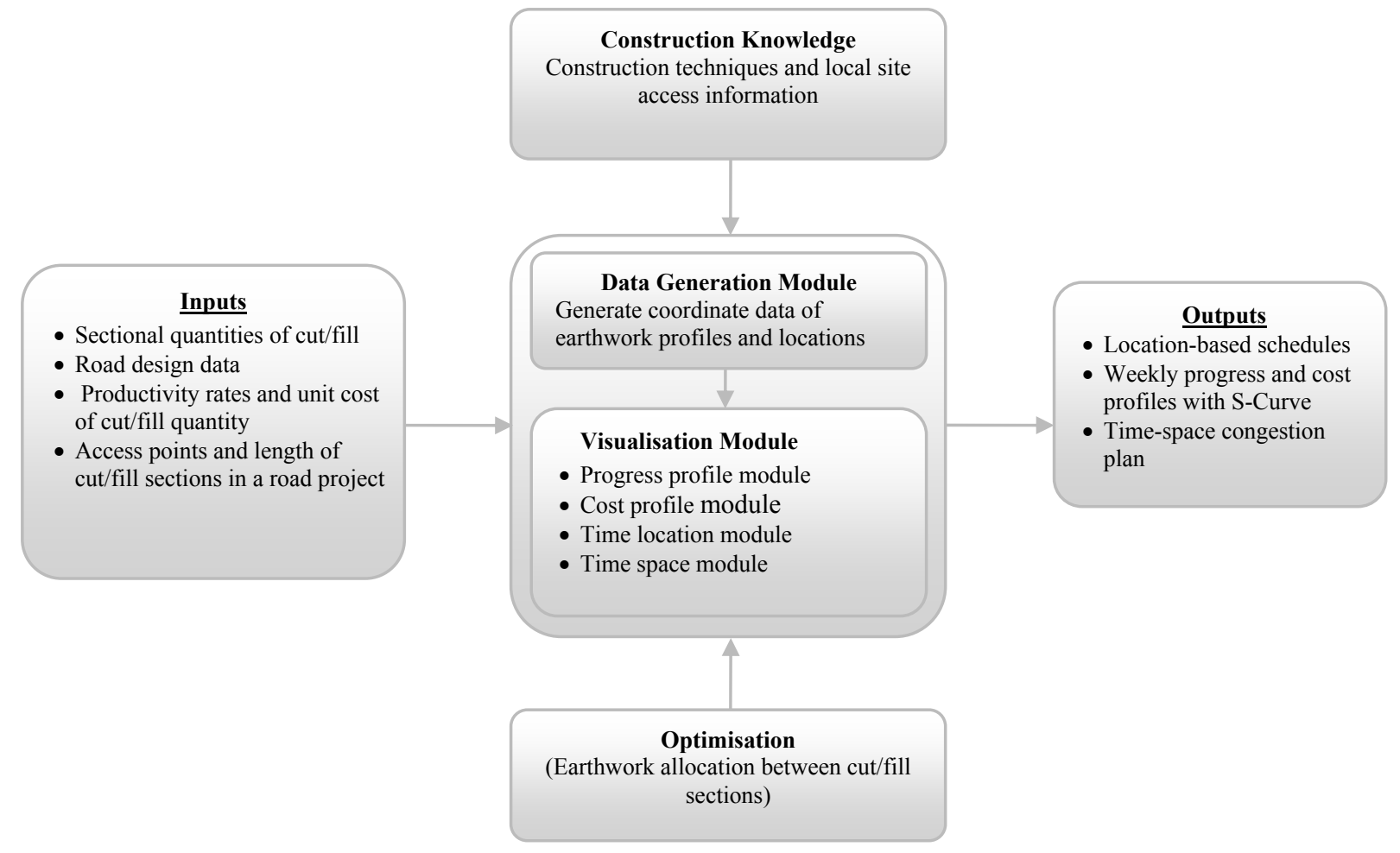

Fig 1 Framework of a prototype of earthwork scheduling and visualisation

This research, however, presented a computer-based prototype model and focused on the case study experiments with the model under scenarios at the construction site. A case study from road projects was utilised for the automatic generation of location-based schedules of earthworks using the algorithm underpinned in the prototype model [15]. Although the prototype model is capable of generating weekly progress profiles, cost profiles and S-curve, this paper discusses mainly the methodology and algorithm, which aid to generate location-based schedules automatically for earthworks. The paper also demonstrates the functions of the model with a case study experiments in a road project. The overall explanations of the model components: inputs, processes and outputs are discussed in the next sections.

\subsection{Prototype model}

This section describes the key components of the prototype model. The sectional quantities of cutting or filling activities, productivity and construction site knowledge base are inputs of the model. The cutting or filling quantity at each station is calculated using road design data including longitudinal section and cross sections. The productivity rate produced by the "RoadSim" simulator is integrated into the model as a main input. The soil characteristics, types of available equipment sets, haulage distance of soil, access road conditions and working efficiency of crew were incorporated within the "RoadSim" simulator. However, earthwork for rock excavation is excluded from this study since the nature of rock excavation is fully different from the normal earthwork operations. The construction knowledge encapsulated from planners and managers was utilised to select the right construction methods under different terrain conditions and soil characteristics considering the available equipment sets for earthworks. The site operational rules and knowledge allow in establishing the sequential relationships amongst listed work activities during the construction operations. The knowledge and operational rules were incorporated within algorithm for the generation of a location-based schedule.

Moreover, an optimisation algorithm was also developed and integrated with the model for optimum allocation of earthworks and the movement direction between cuts and fills, borrows to fills or cut to 
landfills considering economical haulage unit costs. The optimisation algorithm was designed by integrating the characteristics of mass haul diagram, unit cost simulated by "RoadSim" simulator, and Excel solver. The solver was built within MS Excel using a Simplex algorithm for linear optimisation problems. Before producing a location-based schedule, it is vital to identify the possible sources and destinations of earthwork quantities, required for filling and cutting operations in the linear projects. The processes of the prototype include four modules: data generation module, visualisation module, cost profile module and a time-location module. Data generation module processes the input data to generate the coordinate data of weekly locations of the cutting and filling activities, incorporating different production rates. The time location module processes the coordinate data and generates location-based plans for earthwork activities. The next section discusses the generation of locationbased scheduling.

\subsection{Generation of location-based earthwork scheduling}

Location-based scheduling is a planning tool, which is widely applicable in the earthwork planning tasks. The location-based scheduling is also known as time-distance planning, time-chain age planning and linear scheduling method. It enables the design and display of planning and scheduling information of earthwork activities in two dimensions: Location in X-axis and Time in Y-axis or vice versa together with topographical information of a road project. The slope of activities displayed in time location chart represents a rate of production of the earthwork activities. If the slopes of planned activities are compared with the slope of actual activities, they provide visual information of early indication regarding possible of conflicts or overlap between activities during the course of activity progress.

The proposed methodology in the prototype model is original and intelligent to identify the starting and ending location as well as the start and end period of cutting and filling activities at planning stage. It also helps to find the actual information of weekly locations, which ultimately assist to planners and managers for planning the necessary resources more efficiently. The methodology is designed with an arithmetical algorithm that tracks the locations (stations) along a road section which are broken down into weekly or daily schedules, satisfying the linearity characteristics (start and end locations having equal production rate) in the earthwork operations. The equation 7 developed by Shah et al.[15], is being used for identification of the station numbers at each layer throughout the earthwork operations by incorporating the 'variable' productivity data. The productivity data produced by RoadSim [16] are incorporated in the developed equation. The factors that influence the productivity of earthworks are incorporated within the RoadSim programme and produce hourly productivity based on the selected sets of resources and construction equipment.

$$
\mathrm{V}_{\mathrm{r}}=\left[\left\{\sum_{\mathrm{i}=1}^{\mathrm{i}=\mathrm{n}}\left(\mathrm{V}_{\mathrm{i}}\right)-\mathrm{P}\right\} / \mathrm{n}\right]
$$

Whereas,

$$
\begin{aligned}
& V_{r}=\text { Remaining earthwork quantities after progress at each week } \\
& V_{i}=\text { Quantity of earthwork at each station along the selected road section, } i=1,2,3 \ldots \ldots \ldots n . \\
& n=\text { number of working stations along the road section } \\
& P=\text { Productivity used to progress the earthworks }
\end{aligned}
$$

This process is repeated at each layer of cutting or filling sections to achieve the remaining volume $\left(\mathrm{V}_{\mathrm{r}}\right)$ at each station is equivalent to zero (at the design level of road) at the selected working sections along a road project. At each layer, the starting and ending stations are identified and their lengths between the two stations are determined by the algorithm, designed in the model with help of VBA 
programming language. These lengths, at each layer between working stations, increase from the first to the last layer at both cutting and filling sections of the earthwork operation. Similarly, cutting and filling sections are selected according to the earthwork schedule to complete the earthwork operations throughout the construction of a road section. If the cutting or filling sections are longer, these sections are divided into manageable sections and these processes are repeated to achieve the design level of the road.

In this model, two input variables: Productivity rate $(\mathrm{P})$ of earthwork activities produced by "RoadSim" and working length (X) determined by "mass haul diagram" were integrated with the model to search the coordinate of starting and ending locations of working section. The algorithm assists to calculate the coordinate of working locations considering "variable" productivity data throughout the construction operations in a road project. Therefore, coordinates of weekly or daily locations directly depends on the value and unit of productivity i.e. weekly or daily productivity by assuming 40 hours per week or 8 hours per day as standard working time.

The identified coordinate data of locations and time of earthwork activities are stored in a table at first and then exported the coordinate data by programme to generate location-based scheduling. The location-based scheduling has generated automatically. The automatic generated location-based schedule, which is key outputs of the model, provides accurate information of working locations, in the earthwork planning and scheduling. The location-based schedule assists to planners and construction managers in allowing the visualisation and analysis of the status of construction activities on a particular location along the road sections. The next section describes the visual function of the model that assist to planning in visualising the information about weekly locations and space congestion in earthwork operations.

\subsection{Visualisation of time-space scheduling information}

This section presents the development of a visualisation component of the prototype model. This provides the visual information of earthwork scheduling, space congestion, progress profiles, and communicates the construction process sequences with consideration given to location aspects. The Visualisation Module (VM) processes the coordinate data of location-based schedules and transforms them into a visual format to visualise earthwork scheduling information. The VM was developed using the C\# and VBA programming language on MS Excel platform. The required input data was stored in MS Excel worksheets and used as database. Several VBA macros were designed to process input data and generate into visual outputs of the model. The VM imports data using Structured Query Language (SQL) inquiry, and transforms the imported data into a visual representation of scheduling information of earthworks activities in a tabular and graphical format.

A snapshot of the visual outputs of the model is shown in Fig2, which includes weekly progress and cost profiles, cost S-Curve, location-based scheduling information and time-space congestion plan of earthworks in road projects. The location-based plan provides information related to the congested locations and pavement activities such as sub-base, base course and top road surfacing (see Fig 2). The visualisation component also provides tabular information of starting and ending locations on weekly basis throughout the construction operations of earthworks and pavement. The following section describes a case study experiment to evaluate the model's functions (generation and visualisation of location-based scheduling information of earthworks) using real site data from a road project. 


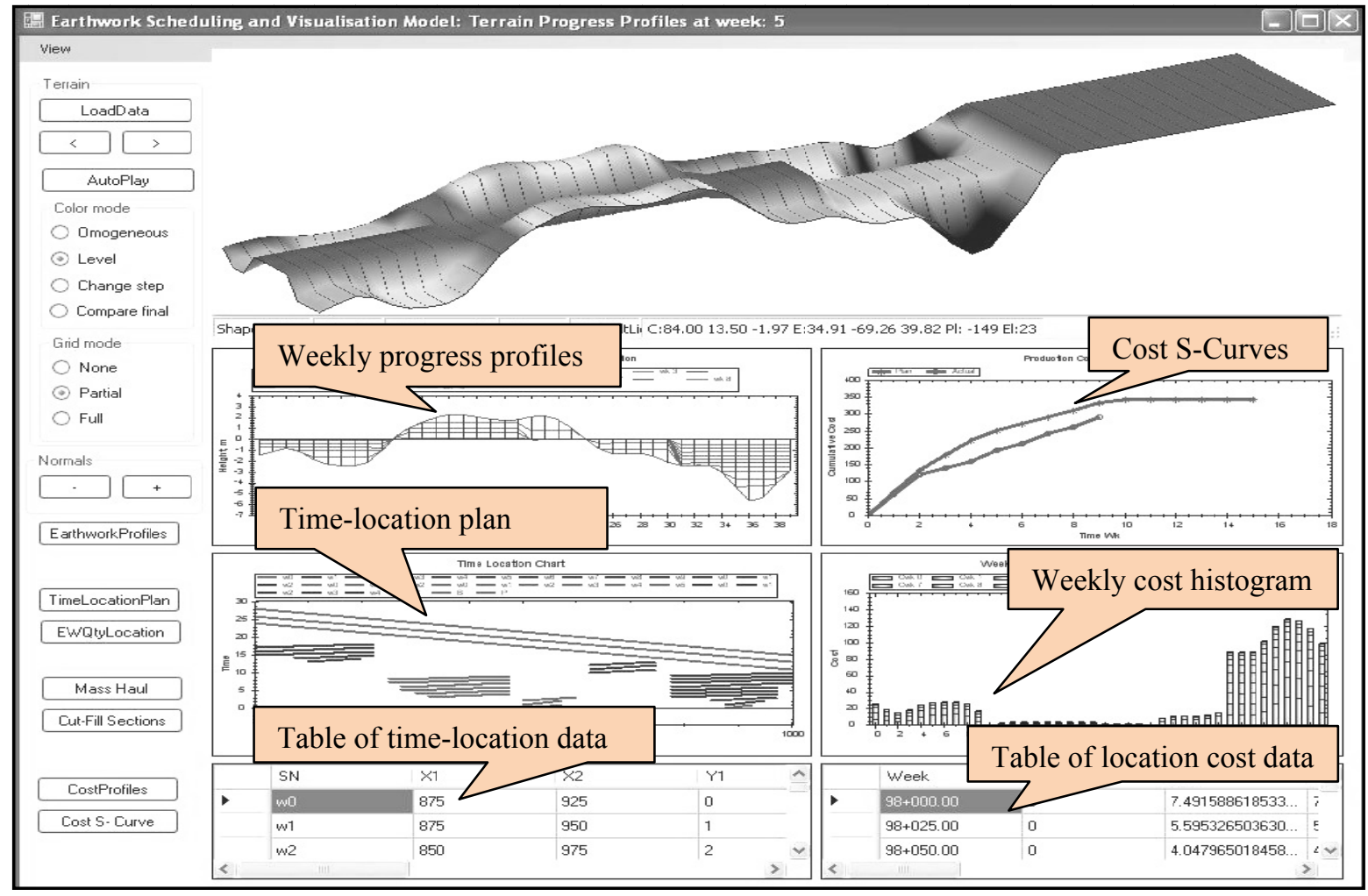

Fig 2 Snapshot of the visual outputs of model showing the location-based scheduling information

\section{Case Study Experiments}

A case study involving 1.0 kilometer of road section of lot no. 3 road project in Portugal was selected to demonstrate the functionalities of the model. Actual road design data including L-section and Xsection is considered, and the sectional quantity of earthwork is calculated assuming typical trapezoidal section at $25 \mathrm{~m}$ intervals along the selected road section. The productivity data of cutting or filling activities is considered as a key factor that affects the construction duration, working locations and numbers of construction layers required to complete earthwork operations. Since the model outputs directly depend on the accuracy of the productivity data, the case study experiment was run to compare the variations in the productivity values between actual site progress and model used values of earthwork activity. The case study results revealed that the actual productivity was lower by $2 \%$ compare to the productivity value produced by the model to generate a location-based schedule for earthwork activity in road projects. The outputs of the model are automatic generation of earthwork progress profiles, 4D terrain surfaces, cost profiles, production cost S-curve and location-based work schedules and visualisation of scheduling information from the location aspects.

A $7 \mathrm{~km}$ road section was selected with the assistance of a company for the validation of the timelocation plan (location-based scheduling) produced by prototype model. The duration of earthworks shown in a time-location plan provided by the company was compared with the duration shown in the time-location plan generated by the prototype model. The comparative results including detailed information of weekly working lengths/locations of a road section, earthwork quantities, productivity, and total duration of the earthworks are presented in Table1. 
Table 1 Comparison of between company-provided and model-generated time-location plan

\begin{tabular}{|c|c|c|c|c|c|c|c|c|c|c|}
\hline \multirow{2}{*}{$\begin{array}{l}\text { S. } \\
\text { N. }\end{array}$} & \multirow{2}{*}{$\begin{array}{l}\text { Road } \\
\text { section }\end{array}$} & \multirow{2}{*}{$\begin{array}{c}\text { Sectio } \\
\text { nal } \\
\text { Lengt } \\
\mathrm{h} \\
(\mathrm{m})\end{array}$} & \multirow{2}{*}{$\begin{array}{l}\text { E/W } \\
\text { Qty. } \\
\left(\mathrm{m}^{3}\right)\end{array}$} & \multirow{2}{*}{$\begin{array}{l}\text { Cut/Fill } \\
\text { Activity }\end{array}$} & \multirow{2}{*}{$\begin{array}{l}\text { Used } \\
\text { Producti } \\
\text { on Rate } \\
\mathrm{m}^{3} / \mathrm{wk}\end{array}$} & \multicolumn{2}{|c|}{$\begin{array}{l}\text { Company- } \\
\text { produced Results }\end{array}$} & \multicolumn{2}{|c|}{$\begin{array}{l}\text { Model- } \\
\text { generated } \\
\text { Results }\end{array}$} & \multirow{2}{*}{$\begin{array}{c}\text { Variatio } \\
\mathrm{n} \text { in } \\
\text { Time }\end{array}$} \\
\hline & & & & & & $\begin{array}{l}\text { Time } \\
\text { (wk) }\end{array}$ & Locations & $\begin{array}{l}\text { Time } \\
\text { (wk) }\end{array}$ & $\begin{array}{c}\text { Locat } \\
\text { ions }\end{array}$ & \\
\hline & $0+000$ & \multirow{2}{*}{925} & 32,400 & Cutting & \multirow{2}{*}{2309} & 14.03 & $0+000$ & 15 & \multirow{2}{*}{ Fig 3} & $6.45 \%$ \\
\hline & $0+925$ & & 34,433 & Filling & & 14.91 & $\begin{array}{c}\alpha \\
0+925\end{array}$ & 15 & & $0.58 \%$ \\
\hline \multirow{2}{*}{2} & $0+925$ & \multirow{2}{*}{1750} & 64,700 & Cutting & \multirow{2}{*}{3464} & 18.68 & $0+925$ & 21 & \multirow{2}{*}{ Fig 3} & $11.06 \%$ \\
\hline & $2+675$ & & 51,352 & Filling & & 14.82 & $\begin{array}{c}\infty \\
2+675\end{array}$ & 16 & & $7.35 \%$ \\
\hline \multirow{2}{*}{3} & $2+675$ & \multirow{2}{*}{925} & 23,357 & Cutting & \multirow{2}{*}{5196} & 4.50 & $2+675$ & 5 & \multirow{2}{*}{ Fig 3} & $10.10 \%$ \\
\hline & $3+600$ & & 36,204 & Filling & & 6.97 & $\begin{array}{c}\alpha \\
3+600\end{array}$ & 8 & & $12.90 \%$ \\
\hline \multirow{2}{*}{4} & $3+600$ & \multirow{2}{*}{3400} & 204,29 & Cutting & \multirow{2}{*}{10392} & 19.56 & $3+600$ & 22 & \multirow{2}{*}{ Fig 3} & $10.64 \%$ \\
\hline & $7+000$ & & 213,16 & Filling & & 19.64 & $7+000$ & 23 & & $10.81 \%$ \\
\hline
\end{tabular}

The comparison results (presented in Table 1) show that model simulated production duration of earthworks is higher by $8.7 \%$ (average) than the company estimated production duration of earthwork for both cutting and filling operations. The duration was calculated by rounding the values for each cut/fill section in case of the model-generated schedule, whereas, the duration was calculated by dividing whole quantities with productivity (production rate) of earthworks for each section in case of the company produced schedule (Table 1). Figure 3 represents a time-location plan of the road project, which includes both the model generated time-location plan in colour limes whereas dotted line represents the company produced and utilised time-location plan. The plan was produced by dividing the road section into four sub-sections $(0+000$ to $0+925,0+925$ to $2+675,2+675$ to $3+600$ and $3+600$ to $7+000)$. Each section was planned with different sets of equipment separately at different production rates (Table 1).

Moreover, several experiments about generating time-location plan for earthworks were carried out at lot no. 5 section in a road construction project in Portugal. The experiments revealed that the actual production time was lower by $2.34 \%$ than the model-simulated production time of earthworks due to variation of soil characteristics at the cutting sections along the road project, which is presumed as a minor variation in earthworks.

Hence, it is concluded that the model-produced location-based schedules or time-location plans are acceptable for earthworks in road construction projects. Consequently, these plans support in improving resource planning and scheduling information of weekly work locations, mobilising sets of construction equipment and required materials including gang size of labours from the location aspects. 


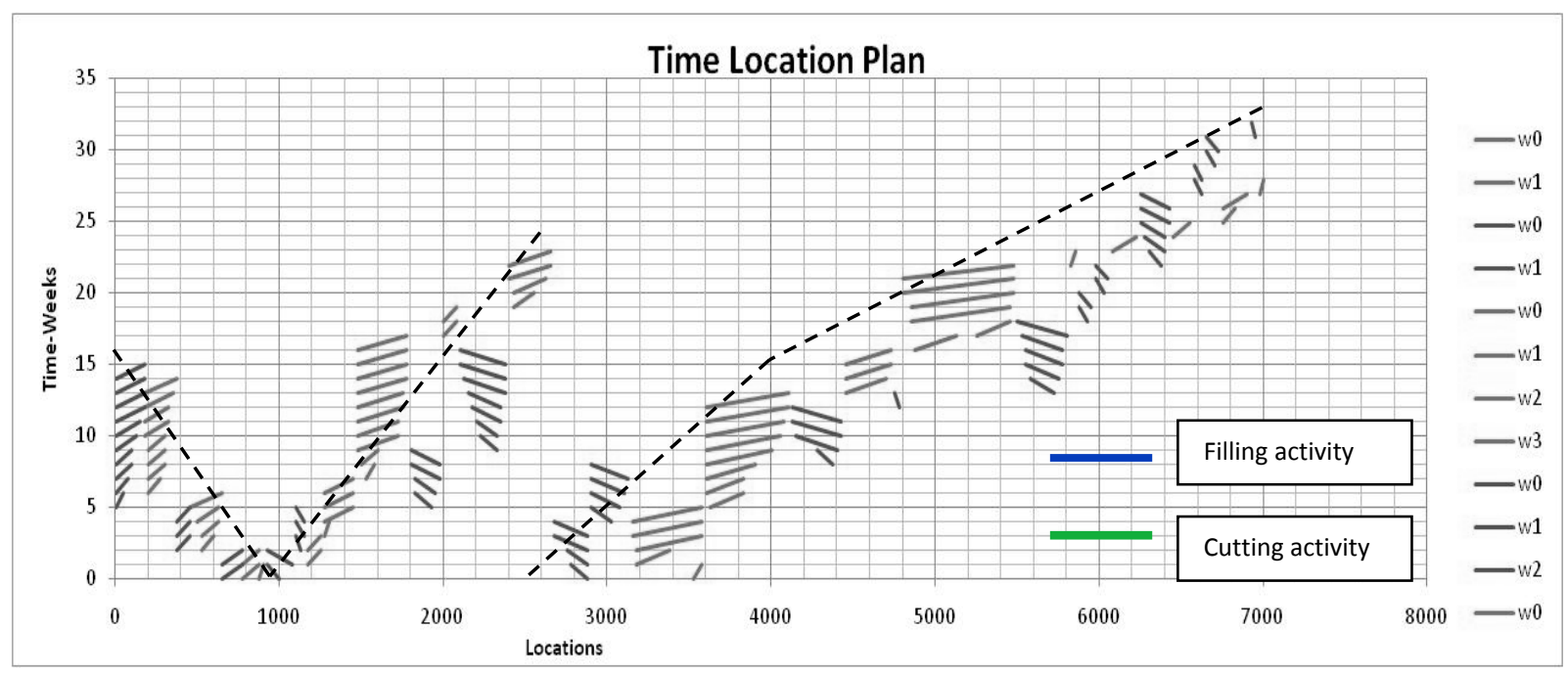

Fig 3 Model-generated time-location plans of a $7 \mathrm{~km}$ road project

\section{Conclusion}

The paper presents the development of a framework and a computer-based prototype model. The model was designed by integrating the road design data; sectional earthwork quantities, productivity rates and unit cost of cut/fill sections and arithmetic algorithms. The model generates automatically the scheduling information of weekly work locations, space congestion plans and resource allocation information for the earthwork projects. A case study experiment was run to demonstrate the functions of the model using site data from road projects. The experiment results revealed that the model provides weekly information of working locations and required resources such as quantity of materials, sets of construction equipment and crew size in earthwork operations. The evaluation from road experts also recommended that the model is a useful tool in supporting the strategic decisions at the planning stage, and helpful to provide the scheduling information more precisely from the location aspects. Running various strategies with the model would allow optimisation of resources, including sets of the construction equipment and crew size, in the earthwork operations at a particular section of a road or railway project.

The findings from the case study experiments found that the model-generated location-based plans are satisfactory and applicable in the linear construction projects like roads or railways, particularly for the earthwork operations. The time-space congestion plan said to identify space congestion in advance and the possibility of equipment being idle at a particular location along the road section. Finally, the paper concluded that the model is a valuable decision supporting tool that assists to the construction and planning managers in mobilising construction equipment more efficiently and visualising the scheduling information of earthworks from the locations aspects. Consequently, the tool is helpful in resource scheduling, progress monitoring, reducing space conflicts and communicating the scheduling information more effectively from the location aspects in earthwork projects like roads and railways. 


\section{References}

1. L. Koskela, "An exploration towards a production theory and its application to construction", PhD Thesis, 200, VTT Publications.

2. F. W. Ahmed and Y. T.Walid, "A Virtual Construction Environment for preconstruction planning”, Journal of Automation in Construction, Vol. 12, pp 139-154, 2002.

3. M. J. Mawdesley, W. H. Askew and S. H. Al-Jibouri, "Site layout for earthworks in road projects", Journal of Engineering Construction and Architectural Management, Vol.11(2), pp 8389, 2004.

4. D. Arditi, B. O. Tokdemir and K. Suh, "Challenging in Line-of-Balance Scheduling”, Journal of Construction Engineering and Management, Vol. 128(6), pp 545-556, 2002.

5. D. J. Harmelink and R. A. Yamin, "Development and application of linear scheduling techniques to highways construction projects", Technical report of FHWA/IN/JTRP-2000/21, October, pp 8-69, 2000.

6. S. Kim and J. S. Russell, "Framework for an intelligent earthwork system Part I system architecture",Journal of Automation in Construction, Vol. 12, pp 1-13, 2003.

7. S. Castro, "Integrated simulation models applied to road construction management", $\mathrm{PhD}$ Thesis, University of Teesside, Middlesbrough, UK, 2005.

8. K. G. Mattila and D. M. Abraham, "Linear scheduling: past research efforts and future directions", Journal of Engineering, Construction and Architectural Management, Vol. 5 (3), pp 294- 303, 1998.

9. D. Arditi, B. O. Tokdemir and K. Suh, "Effect of learning on line-of-balance scheduling", International Journal of Project Management, Vol. (19), pp 265-277, 2001.

10. R. Kenley and O. Seppanen, "Location based management of construction projects: part of a new typology for project scheduling methodologies", Proceedings of the 2009 winter simulation conference, pp 2563-2570, Dec 13-16, 2009, Austin, Texas, USA

11. R. Kenley and O. Seppanen, "Location based management for construction projects: planning, scheduling and control", First edition, 2010, Spon Press, Abingdon, UK.

12. DynaRoad, "DynaRoad: "plan, schedule and control", available online at http://www.dynaroad.fi/pages/index.php. 2006. [Accessed at 15 Jan 2015].

13. TILOS, "Linear Project", TILOS, available online at http://www.tilos.org/software_en.html 2009, (Accessed at 15 Jan 2015).

14. R. K. Shah and N. Dawood, "An innovative approach for generation of a time-location plan in road construction projects", Journal of Construction Management and Economics, 29(5), pp 435-448, 2011.

15. R. K. Shah, N. Dawoodand S. Castro, "Automatic Generation of Progress Profiles for Earthwork Operations using 4D Visualisation Model”, Journal of Information Technology in Construction, Vol (13), pp 491-506, 2008.

16. S. Castro and N. Dawood, "Automating road construction planning with a specific-domain simulation system”, ITcon Vol. 14, p556-573, 2009. 